\title{
MICROFINANCE AND GENDER EMPOWERMENT
}

\author{
THI MINH-PHUONG NGO* AND ZAKI WAHHAJ ${ }^{+}$
}

\begin{abstract}
In the past 30 years, microfinance has carried many promises of social and economic transformation, with the shift towards targeting women being seen as a major strategic move through which the promise of social development could be most effectively delivered. However, ethnographic studies have shown that many women relinquish the use of their loans to male members of the household, belying the empowering promise of microfinance. We propose a simple model of household bargaining which examines how providing women with credit affects production and decision-making power in the household. Following Bergstrom (1996), we account for the roles of both divorce and non-cooperation in the household as relevant fall-back options in the bargaining strategy of each spouse. We show that the introduction of a microcredit programme is likely to have widely heterogeneous impacts, and can adversely affect the bargaining power of some women. We demonstrate that access to credit allows a woman to strengthen her bargaining position through an expansion of her autonomous activities (the causal mechanism hoped for) in a limited number of cases: when she is able to invest her new capital profitably in an autonomous activity, and her husband has no alternative activity in which the same capital would generate comparable returns, or lacks the power to overrule her preferred investment choice. The case in which the availability of credit is most likely to strengthen women's bargaining position in the household is when capital can be invested in a cooperative activity in which both spouses contribute in an important way.
\end{abstract}

JEL Codes: D13, D91, J16.

Date: December 2009

* tn28@soas.ac.uk Center for Development, Environment and Policy (CeDep), Social of Oriental and African Studies (SOAS), 36 Gordon Square, London WC1H 0PD, United Kingdom + zaki.wahhaj@qeh.ox.ac.uk Department of International Development, University of Oxford, 3 Mansfield Rd, OX1 3TB, United Kingdom (Corresponding Author). 


\section{Microfinance and the Promise of Social Change}

In the past 30 years, microfinance has carried many promises of social and economic transformation, with the shift towards targeting women being seen as a major strategic move through which the promise of social development could be most effectively delivered. It is argued that enabling women to generate their own independent income would help tip the balance of power within the household in their favour and allow them to negotiate a larger share of household resources. Because women are more likely than men to invest in household public goods, enlarging the scope for women's (as opposed to men's) employment through access to microcredit is believed to be the most effective channel to deliver wider social benefits (Armendariz de Aghion and Morduch 2005, Khandker 2003, Pitt et al. 2006). ${ }^{1}$

This virtuous sequence of events linking targeting women for the delivery of credit to poverty alleviation is premised on women's enhanced ability to exert greater autonomous control over resources and has been justified on both theoretical and empirical grounds. Empirically, a substantial and growing body of evidence has shown that increasing resources in the hands of women (rather than men's) has greater impacts on family welfare, in particular children's health (child survival and nutrition rates) and education (Duflo 2005, World Bank 2001). ${ }^{2}$ This social motive for targeting women has been a strong motivation behind poverty-oriented microfinance programmes such as FINCA or the Grameen Bank. $^{3}$

\footnotetext{
${ }^{1}$ In addition, because women are believed to be more risk-averse, easier to monitor, and more amenable to the threat of social sanctions than men, targeting women would also contribute to the financial sustainability of microfinance programmes as evidenced by women's higher repayment rates compared to men's. See Cull, Demirguc-Kunt and Morduch (2008) for a recent overview of the financial sustainability debate.

${ }^{2}$ Note Edmonds (2005)'s contrary finding that children aged 13 to 17 were more likely to attend school when they lived with a eligible male recipient of a new pension transfer, than when they lived with an eligible female recipient.

${ }^{3}$ Susan Davis, chair of US -based Grameen Foundation explained "There has been research that shows that when women make financial decisions, greater disposable income goes into improved nutrition, health status, and housing for their children and families. That's why the industry shifted. When Grameen started, it was just trying to reach 50-50 parity between men and women, but then they noticed the difference." http://knowledge.allianz.com/en/globalissues/microfinance/microcredit/davis_microfinance_women_grameen.htn Accessed October 8, 2008. For FINCA, whose borrowers are 70 percent women, see http://www.gdrc.org/icm/finca/finca-2.html. Accessed on October 8, 2008.
} 
Analytically, the foundations for such an approach can be found in bargaining models of the household which posit that household members can obtain a greater share of household resources by improving their fall-back options. Threat or fall-back options capture the level of welfare available to each spouse in case of a breakdown in the bargaining process taking place in the household. The empowering effect of microfinance programmes is expected to materialise through their effects on two types of fall-back options: the utility levels attained by each spouse in case of divorce or exit from the marriage; and the utility levels attained when each spouse retreats to an autonomous sphere within the household. In keeping with this theoretical literature, proxies used in the empirical literature to measure relative bargaining power in the households include assets brought at marriage, unearned income, or inherited assets, over which each spouse retains separate control within marriage, or exogenous policies that affect men and women's outside options such as divorce or employment laws (Adam et al. 2003, Fafchamps et al. 2006, Thomas et al. 2002). All (explicitly or implicitly) take the view that greater family welfare can be attained by increasing women's autonomous control over resources.

However, transferring the above reasoning to microfinance is far from straightforward. While women may readily keep control over cash benefits transferred to them, by contrast, loans enter a complex decision-making process with perplexing impacts on the outcomes of the bargaining process. ${ }^{4}$ In particular, there is congruent evidence that many women relinquish the use of their loans, in part or in whole, to their spouses (Goetz and Gupta 1996, Kabeer 2001, Rahman 1999). For instance, in an ethnographic study of the operations of Grameen Bank in a Bangladeshi village, Rahman (2001) showed that 78 percent of loans granted to women were used by male members of the household (i.e. their husbands or sons). Similarly, Goetz and Gupta (1996) report that 56 percent of loans borrowed by women were invested in male activities. In a study of a group lending programme conducted by one of us in Kyrgyzstan, almost all group loans (97.5 percent), irrespective of the gender of the borrower, were allocated to livestock breeding, an activity traditionally controlled by men with some inputs by women (Ngo 2008).

The fact that women pass on their loans to male members of the household has been interpreted by some as evidence of women losing control over their loans, casting doubt on the empowering potential of microfinance. The focus is on women as primary decisionmakers and having autonomous control over loans use and/or loan management.

\footnotetext{
${ }^{4}$ See Rutherford (2002) for an ethnographic account of the complexity of the financial (loans and savings) portfolio handled by low-income households in Bangladesh.
} 
The observation that women often relinquish their loans to their husbands has led some theoreticians to argue that, in some instances, it may be in the strategic interest of women borrowers to do so. Ligon (2002) observes that even if a woman is able to invest a loan profitably in an autonomous activity, her bargaining position in the household may be weakened if the initiative causes her autonomous income to become more uncertain. In this case, she would be better off handing over the loan money to her husband rather than investing it herself. Van Tassel (2004) offers the explanation that relinquishing control of the loan is a way of ensuring that the husband would help to repay the debt and thereby secure access to future credit in the event that the current loan project fails. ${ }^{5}$

Another interpretation has been proposed by Kabeer (1998, 2001), who argues that women placed in situations of unequal interdependence within the family, and with limited options outside of marriage, may prefer interventions that strengthen the household as a whole rather than seek to improve their individual situations. As Kabeer explained:

\begin{abstract}
"[Women had] a much stronger stake in strengthening cooperation, and minimizing conflict within the family. Unequal interdependence within the family, and women's greater vulnerability outside it, explain why the women loanees sought greater equality within the family as a result of their access to credit rather than greater independence from it. It explains, for instance, the significance they invested in their ability to bring a valued resource into the household and to contribute directly to household income."
\end{abstract}

The scope for women to invest capital in purely autonomous activities is clearly circumscribed by gender norms that delineate the division of labour and responsibilities between men and women in the household and the wider community. ${ }^{6}$ For instance, social conventions and gender norms regarding the divisions of labour may oblige women to remain near the home to take care of children, or restrain their ability to travel to markets. These

\footnotetext{
${ }^{5}$ More specifically, Van Tassel posits that the husband has a preference for more risky investments than the wife, and, in fact, would not find it worthwhile to renew the loan to invest in the wife's preferred safe project. Therefore, the husband has no incentive to repay the current loan to ensure the household's access to future credit if future investments will always be made in the safe project. By transferring control, the woman effectively provides a guarantee that future investments will be in the risky project, thereby giving the husband the incentive to assist in repaying the current debt. We should note that there is some inconsistency in Van Tassel's formulation of control rights within the household, because even when the woman gives up control of the loan, she is assumed to retain ownership of the profits from the investment.

${ }^{6}$ This perspective appears most clearly from ethnographic studies of microfinance, which are rich in contextual details. See Johnson (2004), Kabeer (1998), Kabeer (2001), Mayoux (1999), Rahman (1999).
} 
constraints explain why women are limited to fewer and less profitable business ventures than men (de Mel et al. 2007, 2008, Emran et al. 2006, Johnson 2004, Johnston and Morduch 2007). ${ }^{7}$ Unequal interdependence between spouses also explains why women are more dependent on the contribution of male household members for the conduct of their businesses than men are on women's inputs. Limitations on women's self-employment opportunities has been widely documented. For example, in Bangladesh, where the practice of purdah puts considerable limits on women's mobility in the public space, women who invest their loans in their own activities remain bound to home-based activities (e.g. poultry or milk cow rearing) in line with traditions stipulating that these activities are managed by women. Loans used by men and women in joint enterprises also retain the same gender structure, for example with women making puffed rice or sweet, which are then sold by their husbands (Anderson and Eswaran 2007, Hashemi et al. 1996, Kabeer 1998).

To disentangle how microcredit programmes targeted at women can be expected to shift the balance of power in the household, we develop a simple model of household bargaining where we (i) allow for cooperative endeavours in production between the husband and the wife, and the possibility of investing the loan in such endeavours; (ii) account for the roles of both non-cooperation and the threat of divorce in the bargaining process, and acknowledge that social norms may limit (in different ways) the range of entrepreneurial activity that may be undertaken in marriage and following divorce. Following Bergstrom (1996), we propose a model which accounts for the role of both divorce and non-cooperation in the household as relevant fall-back options in the bargaining strategy of each spouse. Our model contrasts with axiomatic models of intrahousehold bargaining, which solve the bargaining problem by assuming ex-ante what the relevant threat point will be (Lundberg and Pollak 1993, Manser and Brown 1980, McElroy and Horney 1981).

Our approach differs from those of Van Tassel (2004) and Ligon (2002) in that, rather than assuming a binary choice for the use of credit, we allow for its use in a cooperative sphere of production; and distinguish between the possible uses of credit within and outside of marriage. On the other hand, we abstract away from the issue of risky investments and their implications for household bargaining, which has received careful attention in these studies.

\footnotetext{
${ }^{7}$ In a recent study on the profitability of micro-enterprises in Sri Lanka, De Mel, McKenzie and Woodruff (2008) find that mean returns to capital are zero among female-owned enterprises and that more than half of the enterprises owned by women have negative returns, compared to 20 percent for men.
} 
Our modelling choice allows us to explore the possibility of heterogeneous impacts across households of microcredit programmes targeted at women borrowers. Thus, we are able to address one of the key questions within the current debate on women's empowerment and microfinance today: namely, under what conditions, if any, can a policy of targeting women in microcredit programmes, improve their decision-making power and control of resources within the household? We believe that this key policy-related question for research on microfinance and gender empowerment today has not received adequate attention in the existing theoretical literature. Van Tassel (2004) and Ligon (2002) focus, instead, on two specific puzzles from the early experience of microfinance institutions; namely, the substantially higher rates of repayment achieved by targeting women borrowers, and the relinquishment of loans by women borrowers to their spouses.

Given the limits on women's ability to earn an independent income, we pay particular attention to how access to a new resource that enlarges the scope for cooperation in the household affect the relative bargaining power of spouses. Our focus on cooperation in the household echoes recent concerns about the consequences of excluding men in microfinance (Armendariz de Aghion and Roome 2008) or health (Mullany et al. 2005) programmes, when their participation is important for programme success. Since production decisions regarding loan use affect the fall-back options of the spouses, we also explore the situation when the male spouse may have an incentive to appropriate the loan to maintain his own bargaining power within the household.

We find that access to credit allows a woman to strengthen her bargaining position through an expansion of her autonomous activities only under very specific circumstances: when the woman is able to invest her new capital profitably in an autonomous activity and her husband has no alternative activity in which the same capital would generate comparable returns. The case in which the availability of credit is most likely to strengthen women's bargaining position in the household is when capital can be invested in a cooperative activity in which both spouses contribute in an important way. We also show that the impact of any type of intervention depends critically on whether or not divorce is a credible threat point.

The next section sets up our model of household bargaining and interprets it in the context of an intervention providing women with access to new capital. We then represent and distinguish between four types of intrahousehold relations and predict how access to credit affects production and bargaining power in the household in each case. We illustrate the 
model's predictions by drawing on ethnographic studies of the outcomes of microfinance programmes. Section 3 concludes with further discussions of our theoretical results.

\section{Cooperative Gains and Bargaining Power within the Household}

Empirical studies have shown that in many societies, divorce carries a particularly high cost and non-cooperation within the household constitutes a more credible threat-point than divorce for most women. This insight was prominently put forward by Lundberg and Pollack (1994), who define the non-cooperative threat point as a "division of labour based on socially recognized and sanctioned gender roles". Short of marriage dissolution, spouses retreat to 'separate spheres' within the marriage where they each fulfill their gender roles and where the non-cooperative equilibrium is determined by each spouse's voluntary contributions to household public goods (Lundberg and Pollak 1993). ${ }^{8}$

Choosing the relevant threat point has important implications regarding the prediction of household bargaining models. Predictions from divorce-threat bargaining models differ considerably from models that posit non-cooperation as the fall-back option (Adam et al. 2003, Anderson and Eswaran 2007, Pollack 1994). For example, Anderson and Eswaran (2007) are able to reject the prediction from divorce-threat bargaining models that unearned income has a greater impact than earned income on women's bargaining power in Bangladesh, where divorce is highly uncommon. Instead, in line with predictions from bargaining models using non-cooperation as the relevant threat point, they argue that it is the control that women exert over their own earnings in the non-cooperative outcome that can shift the balance of power within the household. Relatedly, they show that there is no difference between pure housewives (who do not contribute to household income) and women working on their husbands' farms because the latter do not exert control over the income generated from their labour.

Nevertheless, in our theoretical analysis of decision-making within the household, we allow for both non-cooperation and exit as strategic options in the bargaining process. There are a number of reasons for taking this approach. First, empirical tests of the divorce-threat model versus the separate spheres model are conducted at the mean; this

\footnotetext{
${ }^{8}$ In traditional patriarchal societies, this involves women meeting their traditional obligations as mothers, wives, and daughters-in-law such as child-bearing and performing household chores. For men, this includes fulfilling their roles as primary breadwinners and meeting their obligations towards their parents, community and kinship group.
} 
does not preclude the possibility that, in specific instances, the woman's exit option does impact upon negotiated decisions within the household. Given our concern with heterogeneous outcomes within households from the introduction of a microcredit programme, our theoretical analysis must take this possibility seriously. Second, the terms of noncooperation may differ substantially between households in developed countries and in developing countries with strongly patriarchal norms. In the latter case, a certain level of violence against women by their husbands may be deemed socially permissible and, therefore, the threat of violence or actual violence may be used in the bargaining process . The possibility of violence under non-cooperation can imply that, in certain instances, leaving the marriage is a realistic option (even if it is not actually undertaken). ${ }^{9}$ Third, while the incidence of divorce in these societies may be low, the incidence of separation initiated by the wife, precisely in situations where she has been subject to or threatened with violence, is substantially higher.

We differentiate between the scope for autonomous activities within marriage, and income opportunities following exit. If an individual, especially a woman, relies on the support and resources available to her as a consequence of her status or position within the community for her autonomous household activity, then she may not have the same opportunities upon exiting the marriage. It is also possible that a woman is constrained in terms of the type of economic activities she can undertake within a marriage because of social conventions, and has more options available to her if she leaves the marriage and is no longer obliged to follow these conventions.

This distinction between opportunities within and outside of marriage also has important implications for credit. A loan taken by the household may be invested in a female activity, but it does not necessarily follow that the woman would be able to retain control of the new asset or enterprise if she leaves the marriage. ${ }^{10}$ On the other hand, a woman may have little scope of investing a loan profitably while she remains married - in which

\footnotetext{
${ }^{9}$ In the context of Bangladesh, the social acceptability of violence against women by their husbands has been documented in various ethnographic studies; e.g. Hartmann and Boyce (1983) and White (1992). The use of the domestic violence as a bargaining tool has been documented by Rahman (1999). Bloch and Rao (2001) provide econometric and qualitative evidence, using data from three South Indian villages, that domestic violence against women is being used strategically by their husbands to extract transfers from the wives' parents.

${ }^{10}$ Bina Agarwal argues that, traditionally, women in South Asia have had very weak property rights, both in the written law and in practice, and that divorced women, even those from very prosperous households, many find themselves in a state of destitution because of their lack of independent rights in property (Agarwal, 1994). Whether women may have stronger de facto rights to property acquired with loans given to them by MFIs remains an open question.
} 
case, the loan may be invested in a male or cooperative activity or the household may not participate in the loan programme at all - but the existence of the programme may nevertheless improve her exit option. The exact nature of the impact would depend on the economic opportunites within the community and the socially defined gender norms regarding these opportunities; as well as on the specific skills of the household members.

For these reasons, participation in a credit programme need not affect the income opportunities of the spouses following exit; while the availability of a credit programme may improve the spouses' exit options even if it is not used to make investments in autonomous activities within the marriage.

We model bargaining within the household as a game of alternating offers with both divorce (also referred herein as the exit or outside option) and non-cooperation within the household (in the definition proposed by Lundberg and Pollak recalled above) as relevant fall-back options. ${ }^{11}$ In the following section, we develop the model and discuss its main insights in the context of development interventions that seek to shift the balance of power within the household with the aim of achieving broader societal transformations.

2.1. A Bargaining Model of the Household. Imagine a household consisting of a husband, $h$ and a wife $w$. They can engage in production in a number of different activities, represented by the set $\mathcal{S}$. Each productive activity requires assets that are specific to that activity - for example, a husking machine for husking paddy - and so we represent household assets by a vector $\mathbf{k}=\left(k_{1}, . ., k_{S}\right)$, where $k_{s}$ is the value of assets specific to activity $s$. Each activity also involves performing various tasks that, because of the prevailing gender-related norms, can only be performed by a man, while others can only be performed by a woman. Therefore, a unit of effective labour by the husband in an activity is not equivalent to a unit of effective labour by the wife, and output depends on the specific levels of each. Each spouse is endowed with one unit of labour per period. Formally, output in activity $s$ is given by

$$
\begin{aligned}
y_{s} & =g_{s}\left(k_{s}, l_{s}\right) \\
l_{s} & =\gamma_{s}\left(l_{s}^{h}\right)^{\theta_{s}}\left(l_{s}^{w}\right)^{1-\theta_{s}}
\end{aligned}
$$

\footnotetext{
${ }^{11}$ Kanbur and Haddad (1994) propose a similar model of household bargaining and touch upon some of the results discussed here. However, given our focus on microfinance interventions and gender empowerment, our interpretation of the model and the results are considerably different from those of Kanbur and Haddad (who consider the question whether households grow more or less equal as they grow richer). Moreover, our analysis is carried out in a more general setting.
} 
where $l_{s}^{h}, l_{s}^{w}$ measure the labour input by the husband and the wife, respectively, in activity $s$.The parameter $\theta_{s}$ captures the relative importance of male and female labour, and $\gamma_{s}$ the combined skill level of the couple, in the activity concerned. We assume $g_{s}($.$) is weakly$ increasing and concave in both inputs.

Since we wish to examine the effects of credit on bargaining and cooperation within the household, we consider the case where the household has three productive activities: $\mathcal{S}=\{m, f, c\}, \theta_{m}=1, \theta_{f}=0, \theta_{c} \in(0,1)$ (the letters stand for 'male', 'female' and 'cooperative'). Thus, the husband and wife can undertake production independently in activities $m$ and $f$ respectively, but some labour input from both is required for positive output in activity $c$.

At the end of production, total household income is given by $y=\sum_{s \in S} y_{s}$ (we assume, for ease of notation, that each output has a price of 1 ). In this section, we assume that the income is spent on a single consumer good, which can be consumed privately by either $h$ or $w$. Both spouses derive utility from own consumption only. Furthermore, utility from consumption of the private good exhibits constant absolute risk aversion: $U^{i}(x)=-\exp \left(-r^{i} x\right)$, a functional form that allows for the Nash bargaining solution to be computed with ease. Furthermore, for ease of exposition, we let $r^{h}=r^{w}{ }^{12}$. These simplying assumptions are made primarily to illustrate the basic properties of the bargaining game. In section 2.3, and for the subsequent analysis relating to credit, we consider a more general setting for household consumption, allowing for $n$ different consumption goods, which may include both private and household public goods.

The husband and the wife have control rights over the output from activities $m$ and $f$ respectively. Either spouse may have full control rights over output in activity $c$, without affecting our analysis: as the spouse without control rights would refuse to provide labour for this activity, output would equal zero. Therefore, in the absence of an agreement about the allocation of labour and expenditures, each spouse devotes all her labour to her own activity, and uses the resulting income for private consumption. The autarkic incomes

\footnotetext{
${ }^{12}$ We feel there is no loss of understanding from these simplifying assumptions as the effect of riskaversion on bargaining is well-understood from previous work: Roth (1979) and Kihlstrom, Roth and Schmeidler (1981) have shown that increasing an agent's aversion to risk lowers his share in the outcome of bargaining. Therefore, if one spouse is more risk-averse, then he or she would do worse in the bargaining game. If utility exhibited decreasing absolute risk aversion, then providing additional income to one spouse would strengthen his bargaining position because of a decrease in risk-aversion, independently of any effect on his threat point.
} 
and expenditures are given by $y_{a}^{h}=g_{m}\left(k_{m}, \gamma_{m}\right), y_{a}^{w}=g_{f}\left(k_{f}, \gamma_{f}\right)$. This corresponds to the outcome described as 'separate spheres' by Lundberg and Pollak (1993).

Although $h$ and $w$ would also engage in autonomous production in the event of divorce, their incomes in this case need not correspond to their 'separate spheres' incomes. This is because social norms may impose (or relax) constraints on the types of assets that they can control and the types of activities they can undertake within a marriage. Therefore, we represent income levels following divorce by a different set of variables, $\mathbf{y}_{e}=\left(y_{e}^{h}, y_{e}^{w}\right)$.

To model the process whereby the couple reach an agreement, we make use of the household bargaining game proposed by Bergstrom (1996) and Kanbur and Haddad (1994). The husband and wife can propose an allocation of labour and consumption expenditures in alternate periods, which the spouse can then accept or refuse. If an offer is accepted, then it becomes the standing agreement according to which resources are allocated within the household thereafter, unless it is rejected by the spouse in a subsequent period. When there is no standing agreement, the spouses allocate labour and spend their incomes independently. In addition, either spouse $i$ may choose to walk away from the marriage in any period (before production takes place), in which case he or she would receive the income $y_{e}^{i}$ in each period thereafter (once the marriage has broken down, there is no scope of renegotiation possible).

Formally, suppose $h$ makes offers in periods $2 t-1$ and $w$ makes offers in periods $2 t$, for $t=1,2, \ldots \infty$. There are three stages of decision-making within each period as follows:

Stage 1: If there was no agreement in place in the previous period, then the current offerer can propose an allocation of labour $\left(l_{s}^{h}, l_{s}^{w}\right)_{s \in \mathcal{S}}$ and shares in total expenditure for each spouse $(\alpha, 1-\alpha)$. This then becomes the 'standing offer'. Alternatively, the current offerer can choose to exit the marriage at this stage.

Stage 2: If there was an agreement in place in the previous period or a standing offer, then the spouse of the offerer must choose whether to (continue to) accept or reject it. If the offer or agreement is rejected, there is no agreement for the remainder of the period. If it is accepted, then there is an agreement in place corresponding to the 'standing offer' or previous agreement. Alternatively, the spouse can choose to exit the marriage at this stage. 
Stage 3: If there is an agreement in place, then resources are allocated according to the agreement. If not, then the spouses individually choose to allocate labour across productive activities, and spend the incomes over which they have control rights.

In the description above, we have assumed, implicitly, that when a couple come to an agreement, they are able to commit to divide the income generated from the cooperative activity at the end of production process in accordance with the income shares agreed upon $^{13}$. Under this assumption, any rational proposal will involve an efficient allocation of labour resources within the household; because an offer that involves an efficient allocation of labour can always be made more attractive to both spouses than another which does not. Thus, the total household income in any cooperative agreement will be given by the following maximisation problem:

$$
y(\mathbf{k}, \gamma)=\max _{\left(l_{s}^{h}, l_{s}^{w}\right)_{s \in \mathcal{S}}} \sum_{s \in \mathcal{S}} g_{s}\left(k_{s}, \gamma_{s}\left(l_{s}^{h}\right)^{\theta_{s}}\left(l_{s}^{w}\right)^{1-\theta_{s}}\right)
$$

subject to

$$
\sum_{s \in \mathcal{S}} l_{s}^{i} \leq 1 \text { for } i=h, w
$$

where $\mathbf{k}=\left(k_{m}, k_{f}, k_{c}\right), \boldsymbol{\gamma}=\left(\gamma_{m}, \gamma_{f}, \gamma_{c}\right)$.

Thus, the only substantive issue to be decided upon in the bargaining process is how the income $y(\mathbf{k}, \gamma)$ will be divided between the spouses. In effect, we have here the bargaining game analysed by Rubinstein (1982) with the modification introduced by Binmore $(1985)^{14}$. Binmore showed that the two parties reach an agreement immediately and, if the time lapse between proposals is infinitesimally small, then the total income shares of the two parties are given by the solution to the following problem:

$$
\alpha\left(\mathbf{k}, \boldsymbol{\gamma}, \mathbf{y}_{e}\right)=\arg \max _{\alpha \in[0,1]}\left[U(\alpha y)-U\left(y_{a}^{h}\right)\right]\left[U(\beta y)-U\left(y_{a}^{w}\right)\right]
$$

\footnotetext{
${ }^{13}$ This assumption is essential for the spouses to be able to participate in the cooperative activity. However, they need not be able to commit to make transfers from the income generated by their independent activities because any agreement that requires them to do so cannot arise in equilibrium: the spouse who is required to make such a transfer would be better off under non-cooperation.

${ }^{14}$ Note that, unlike Rubinstein's bargaining game, spouses may choose to reject an offer that was accepted in a preceding period. However, as noted by Bergstorm (1996), it is never optimal for either spouse to do so. Given the stationary environment, if it is optimal for a spouse to accept an offer in some period $t$, it is also optimal to accept the standing agreement corresponding to this offer in subsequent periods.
} 
subject to

$$
\begin{aligned}
& U(\alpha y) \geq U\left(y_{e}^{h}\right) \\
& U(\beta y) \geq U\left(y_{e}^{w}\right)
\end{aligned}
$$

where $\beta=1-\alpha$. Here, $\alpha$ and $\beta$ are the income shares of the husband and wife respectively. It is evident from the maximisation problem described in (2) that the utility levels achieved under non-cooperation and from divorce both influence the outcome of bargaining. For constant absolute risk aversion utility (and the same degree of risk aversion for both spouses), the solution to the bargaining problem in (2) takes a simple form:

$$
\begin{aligned}
& y_{e}^{h} / y \text { if } \frac{1}{2}\left(1+\frac{y_{a}^{h}-y_{a}^{w}}{y}\right)<y_{e}^{h} / y \\
\alpha\left(\mathbf{k}, \gamma, \mathbf{y}_{e}\right)= & 1-y_{e}^{w} / y \text { if } \frac{1}{2}\left(1+\frac{y_{a}^{w}-y_{a}^{h}}{y}\right)<y_{e}^{w} / y \\
& \frac{1}{2}\left(1+\frac{y_{a}^{h}-y_{a}^{w}}{y}\right) \text { otherwise }
\end{aligned}
$$

It is evident from (3) that a spouse's share of total income in the outcome of bargaining depends on the relative values of incomes under non-cooperation, unless this value falls below the income attained from leaving the marriage. In the latter case, one receives, in the bargaining game, exactly the income obtained from exit, while the spouse takes the rest of total household income. Intuitively, a spouse who can fend for herself in a noncooperative household will not be pressured by her partner into accepting an agreement that is biased against her in exchange of a return to cooperation. By contrast, if she has little autonomy within the household, she may acquiesce to an unfavourable agreement to end a conflict. In the second case, a strong exit option protects her from having to suffer an arrangement that is very biased against her, for when faced with the prospect of such an arrangement, her divorce option becomes a credible threat.

The axiomatic approach adopted by Lundberg and Pollak (1993) overlooks the role played by the exit options in the bargaining process when one spouse has little scope of autonomy within the household. Manser and Brown (1980) and McElroy and Horney (1981), also using an axiomatic approach, allow the exit options to affect the outcome of bargaining, but, as pointed out by Bergstrom (1996), not in the manner that is predicted by noncooperative bargaining theory. By explicitly modeling the bargaining process, we are able to show precisely how both the possibility of non-cooperation and divorce affect decision-making within the household. 


\subsection{An Interpretation of the Model in the Context of Household Bargaining.}

Before considering how this framework may be used to investigate the impact of a microcredit programme on bargaining power within the household, we discuss briefly how the 'male', 'female' and 'cooperative activities' and the corresponding parameters $\gamma_{m}, \gamma_{f}$, and $\gamma_{c}$ should be interpreted. Note that the 'female' activity is one that the woman is able carry out within the limits of the socially recognised division of labour for her gender, without the cooperation of her spouse. In the absence of a cooperative agreement, the gender norms also recognise her right to retain control over this income. In a patriarchal setting, women may be dependent on men in carrying out their entrepreneurial activities at least at some stage of production or marketing. In this case, the productive activity should be classified as 'cooperative' within this framework rather than 'female'. ${ }^{15}$ Likewise, a productive activity that is carried out primarily by men but relies on some input from the female spouse, and from which she can credibly threaten to withdraw her cooperation, should be classified as a 'cooperative' rather than a 'male' activity.

The parameters $\gamma_{m}$ and $\gamma_{f}$ can serve to capture heterogeneity across households in individual skill levels in autonomous activities, and $\gamma_{c}$, the ability of the spouses to work together in an activity that requires coordination and cooperation. For example, a low value of $\gamma_{c}$ can represent an extremely conflictual relationship where there is little scope of cooperation between the spouses. In this case, the spouses are likely to engage in largely autonomous activities. ${ }^{16}$ A household where the female spouse has strong entrepreneurial skills, and can operate an entreprise independently of her husband would be characterised by a high value of $\gamma_{f}{ }^{17}$ If a woman who has no opportunity for work other than on her husband's farm, the household would be characterised by low $\gamma_{f}$. Moreover, if her input in farm work is easily substitutable by the man, then $\theta_{c}$ is close to 1 and $\gamma_{m}$ is close to $\gamma_{c}$.

\footnotetext{
${ }^{15}$ For example, in the context of Bangladeshi rural households, Goetz and Gupta (1996) note that "the household is a joint venture, and the gender division of labor is such that full, individual control of the productive process is virtually impossible for women given the gendered nature of access to markets." (p.53)

${ }^{16}$ This equilibrium is equivalent to the situation described by Kabeer (2001) as "divorce within marriage" (p.74). The spouses remain married because of the social stigma associated with divorce.

${ }^{17}$ Kabeer (1998) provides a number of examples of women who can be placed in this category. In some cases, they had overcome traditional gender restrictions: one earned as income as an itinerant trader, another owned a grocery shop in the main bazaar. Others had found an effective solution within these restriction such as the woman who reared a cow and sold its milk 'in the neighbourhood', thus not having to rely on a male household member for marketing.
} 
The Impact of a Development Programme on Intra-Household Bargaining:

The model of household bargaining developed in the previous section can be used to examine the effects of a development intervention that provides households productive assets or improves the productivity of household members in specific activities. In the case of a single private consumption good and CARA utility, the impacts are readily apparent from equation (3). Here, we provide a brief discussion of the comparative statics results under these assumptions. A more general (and weaker) version of these results will be presented in the next section.

Comparative Statics Results with CARA utility:

(1) If the divorce threat is not a binding constraint for either spouse, then

(a) an intervention that increases household assets in the cooperative activity, $k_{c}$, or increases the household's productivity in the joint activity, leads to a decrease in $\alpha^{*}$ if $\alpha^{*}>\frac{1}{2}$, an increase in $\alpha^{*}$ for $\alpha^{*}<\frac{1}{2}$, and has no impact on $\alpha^{*}$ if $\alpha^{*}=\frac{1}{2}$;

(b) an intervention that increases the level of household productive assets, or increases productivity, in the male (female) autonomous activity leads to an increase (decrease) in $\alpha^{*}$;

(c) a small increase in the incomes from the exit options, $y_{e}^{h}$ or $y_{e}^{w}$, such that the divorce threat constraints remain slack, will have no impact on $\alpha^{*}$; for a sufficiently large increase in $y_{e}^{i}, i \in\{h, w\}$, the constraint for spouse $i$ will begin to bind, and $\alpha^{*}$ will shift in favour of this spouse.

(2) If the divorce threat is a binding constraint for the wife, then

(a) an increase in $k_{m}$ or $\gamma_{m}$ will lead to an increase in $\alpha^{*}$;

(b) a small increase in $k_{s}$ or $\gamma_{s}$, for $s=f$ or $c$, such that the wife's constraint continues to bind following the increase, will lead to an increase in $\alpha^{*}$; for sufficiently large increases in these variables, the wife's constraint becomes slack and the the impact on $\alpha^{*}$ is as described by the results $1(\mathrm{a})$ and $1(\mathrm{~b})$;

(c) an increase in $y_{e}^{w}$ will lead to a decrease in $\alpha^{*}$; a small increase in $y_{e}^{h}$ will have no impact on $\alpha^{*}$ but a sufficiently large increase in $y_{e}^{h}$ will lead to the dissolution of marriage.

(3) If the divorce threat constraint is binding for the husband, we obtain the effects corresponding to those described in part 2 . 
The result in 1(b) is well-known from the literature on intra-household bargaining: increasing the scope of autonomy of one spouse yields her a greater share of household resources. More significantly, the result in 1(a) indicates that an increase in the gains from cooperation also shifts relative bargaining powers within the household (as measured by $\alpha^{*}$ ) in favour of the more disempowered spouse. 1(c) indicates that for households where the exit options do not serve as a credible threat in the bargaining process, a small improvement in income earning opportunities that lie outside the range that is socially approved will have no impact on welfare or bargaining power within the household.

The results also indicate considerable heterogeneity in impacts across households. Where the exit option serves as a credible threat, a small increase in the gains of cooperation can actually decrease the income share of the spouse who is against her participation constraint (result 2(b)). In addition, a small increase in her range of economic opportunities within marriage can similarly decrease her share of the surplus from cooperation (result 2(b)). By contrast, strengthening her exit option will lead to an increase in her share (result $2(\mathrm{c}))$.

The results in 2(b) have a simple intuitive explanation. When exit from the marriage becomes a credible threat point, there is, in effect, no more bargaining taking place within the household. The better-off spouse need only ensure that his partner is receiving just enough utility within the marriage so as not to opt for her exit option. As the household becomes richer, it becomes cheaper for him to do so: his partner will be content with staying in the marriage for an even smaller share of the gains from cooperation. ${ }^{18}$

2.3. Multiple Consumption Goods. In this section, we extend the analysis to a setting where there are $L>2$ consumption goods, including both private and household public goods. Let $\mathbf{p}=\left(p_{1}, p_{2}, . ., p_{L}\right)$ be the prices of the $L$ goods, and denote by $\mathbf{x}=\left(x_{1}, x_{2}, \ldots, x_{L}\right)$ a consumption bundle which provide utility levels $U^{h}(\mathbf{x})$ and $U^{w}(\mathbf{x})$ to the husband and wife respectively. In this setting, the husband and wife would bargain, not over income shares but over the level of expenditure on each commodity. However, the nature of the bargaining game is such that any cooperative agreement agreed upon will involve an efficient level of expenditures; i.e. given the household budget, the utility levels attained in the agreement will be on the utility possibility frontier. Therefore, given total household income $y$, any consumption bundle agreed upon will belong to the

\footnotetext{
${ }^{18}$ See Kanbur and Haddad (1994), who find similar results.
} 
set $\{\mathbf{x}(y, \lambda): \lambda \in(0, \infty)\}$ where

$$
\mathbf{x}(y, \lambda)=\arg \max _{\mathbf{p} . \mathbf{x} \leq y} U^{h}(\mathbf{x})+\lambda U^{w}(\mathbf{x})
$$

Thus, any bargaining solution can be fully summarised by the parameter $\lambda$. Here, $\lambda$ is the wife's relative pareto weight, with the husband's pareto weight being fixed at 1 . Note that $\mathbf{x}(y, 0)$ represents the household expenditures that would result if they were decided upon entirely by the husband, while $\mathbf{x}(y, \infty)$ represents the expenditures that the wife would choose on her own. We can say that the husband (wife) has a stronger preference for good $l$ at income level $y$ if $x_{l}(y, 0)>x_{l}(y, \infty)\left(x_{l}(y, 0)<x_{l}(y, \infty)\right)$. Then it is straightforward to show that as $\lambda$ increases, the household spends more on goods for which the wife has a stronger preference and less on goods for which the husband has a stronger preference at the given income level. In this sense, $\lambda$ can be said to capture decision-making authority or 'say' within the household.

To facilitate the analysis of the bargaining game, we define an indirect utility function:

$$
V^{i}(y, \lambda)=U^{i}(\mathbf{x}(y, \lambda)) \text { for } i=h, w
$$

Thus $V^{i}(y, \lambda)$ is the utility obtained by spouse $\mathrm{i}$ in an efficient agreement when total household income equals $y$ and the wife's relative pareto weight is $\lambda$.

Expenditure levels under non-cooperation would depend on the precise nature of the subgame played when expenditure decisions are made non-cooperatively. In particular, Lundberg and Pollak (1993) has shown that the equilibrium attained under non-cooperation is sensitive to presence or absence of separate spheres in consumption and on whether the spouses can make intra-household transfers. For our purpose, the relevant issue is how utility levels under non-cooperation respond to changes in autarkic income levels. Therefore, rather than making explicit the subgame played in non-cooperation, we denote the utility levels attained by indirect utility functions $\tilde{V}^{i}\left(y_{a}^{h}, y_{a}^{w}\right)$, for $i=h, w$, and consider each possible case highlighted by Lundberg and Pollak (1993).

Case (i): if there are separate spheres of household expenditures and no possibility of intra-household transfers under non-cooperation, then $\tilde{V}_{i}^{i}>\tilde{V}_{j}^{i}$ for $j \neq i^{19}$;

\footnotetext{
${ }^{19}$ We use $\tilde{V}_{j}^{i}$ to denote $\frac{\partial \tilde{V}^{i}}{\partial y_{a}^{j}}$.
} 
Case (ii): if there are separate spheres of household expenditures, but intra-household transfers are possible, and spouse $\mathrm{i}$ makes positive transfers to $\mathrm{j}$ in equilibrium, then $\tilde{V}_{i}^{i}=\tilde{V}_{j}^{i}$ for $j \neq i$

Case (iii): if there are household public goods, and each spouse spends a positive amount on each household public good, then $\tilde{V}_{i}^{i}=\tilde{V}_{j}^{i}$ for $j \neq i$ (Lundberg and Pollak, 1993);

Note that, in each of these cases, $\tilde{V}_{i}^{i}>0$. As we have argued that the outcome of bargaining will involve an efficient level of consumption expenditures, the bargaining solution for the general case is given by the following maximisation problem:

$$
\lambda\left(\mathbf{k}, \boldsymbol{\gamma}, \mathbf{y}_{e}\right)=\arg \max _{\lambda \in(0, \infty)}\left[V^{h}(y, \lambda)-\tilde{V}^{h}\left(y_{a}^{h}, y_{a}^{w}\right)\right]\left[V^{w}(y, \lambda)-\tilde{V}^{w}\left(y_{a}^{h}, y_{a}^{w}\right)\right]
$$

subject to

$$
V^{i}(y, \lambda) \geq \hat{V}^{i}\left(y_{e}^{i}\right) \text { for } i=h, w
$$

where $\hat{V}^{i}($.$) is the indirect utility function for welfare from exiting the marriage. { }^{20}$

We consider, first, the situation where the constraints imposed by the exit option do not bind. Then $\lambda\left(\mathbf{k}, \boldsymbol{\gamma}, \mathbf{y}_{e}\right)$ is given implicitly by the following equation:

$$
\lambda=\frac{V^{h}(y, \lambda)-\tilde{V}^{h}\left(y_{a}^{h}, y_{a}^{w}\right)}{V^{w}(y, \lambda)-\tilde{V}^{w}\left(y_{a}^{h}, y_{a}^{w}\right)}
$$

Graphically, this solution is given by the point on the utility possibility frontier where the tangent is perpendicur to the straight line passing through this point and the point representing the non-cooperative utility levels. To determine how $\lambda$ responds to a development intervention that affects household productivity in the different activities, or to changes in the level of household assets, we differentiate throughout (6) with respect to the relevant parameter. Thus, we obtain

$$
\frac{d \lambda}{d v} \equiv \frac{y_{v}\left(V_{y}^{h}-\lambda V_{y}^{w}\right)-\tilde{y}_{v}^{h}\left(\tilde{V}_{h}^{h}-\lambda \tilde{V}_{h}^{w}\right)+\tilde{y}_{v}^{w}\left(\lambda \tilde{V}_{w}^{w}-\tilde{V}_{w}^{h}\right)}{V^{w}-\tilde{V}^{w}+\lambda V_{\lambda}^{w}-V_{\lambda}^{h}}
$$

where $v=k_{m}, \gamma_{m}, k_{c}, \gamma_{c}, k_{f}$, or $\gamma_{f} \cdot{ }^{21}$ From equation (7), it is possible to distinguish between two distinct effects of any intervention on decision-making authority within the household, as measured by $\lambda$. The first is an income effect which (ignoring the denominator which, it can be shown, is always positive) is equal to $y_{v}\left(V_{y}^{h}-\lambda V_{y}^{w}\right)$. If preferences can be represented by a CES utility function (of the form $U^{i}(\mathbf{x})=\sum_{l} \alpha_{l}^{i}\left(x_{l}\right)^{\rho}$ ), then it

\footnotetext{
${ }^{20}$ Formally, $\hat{V}^{i}\left(y_{e}^{i}\right)=\max _{\mathbf{p} \cdot \mathbf{x} \leq y_{e}^{i}} U^{i}(\mathbf{x})$.

${ }^{21}$ We use the following abbreviated notation: $y_{v}=\frac{\partial y}{\partial v}, \tilde{y}_{v}^{i}=\frac{\partial \tilde{y}_{v}^{i}}{\partial v}, V_{y}^{i}=\frac{\partial V^{i}}{\partial y}$, and $V_{\lambda}^{i}=\frac{\partial V^{i}}{\partial \lambda}$.
} 
can be shown that $V_{y}^{h}-\lambda V_{y}^{w} \gtreqless 0$ for $\lambda \lesseqgtr \lambda_{e}(y)$, where $\lambda_{e}(y)$ is defined implicitly by the equation $\lambda V_{y}^{w}(y, \lambda)=V_{y}^{h}(y, \lambda)$ (see proof of Propostion 2.1). In other words, the income effect causes $\lambda$ to move towards $\lambda_{e}(y)$. In the case of a symmetric utility possibility set, $\lambda_{e}(y)=1$, and, in this sense, the income effect can be said to make decision-making authority within the household more egalitarian.

When the intervention is in the cooperative sphere, there is only an income effect on $\lambda$ as described above. However, if the intervention is in the male or female sphere of autonomous activity, there is an additional effect on $\lambda$ caused by a shift in the noncooperative threat point. This 'threat-point effect' equals $-\tilde{y}_{v}^{h}\left(\tilde{V}_{h}^{h}-\lambda \tilde{V}_{h}^{w}\right)$ for an intervention targeted at the male activity, and $\tilde{y}_{v}^{w}\left(\lambda \tilde{V}_{w}^{w}-\tilde{V}_{w}^{h}\right)$ when it targets the female activity (again ignoring the denominator which is the same as in the income effect). It should be clear from the preceding discussion on the non-cooperative threat point that the signs of the threat-point effects are ambiguous. Indeed, for cases (ii) and (iii) noted above, the threat-point effects favour whichever spouse has greater decision-making authority in the initial situation (i.e. it depends on whether $\lambda$ is smaller or greater than one) whether the intervention occurs in the male or female activity. This suggests that an investment in the autonomous sphere of one spouse will not necessarily strengthen her or his decision-making authority beyond any income effect if that spouse were initially in a weaker bargaining position. The following proposition summarises the results discussed here.

Proposition 2.1. Suppose preferences can be represented by a CES utility function. If the divorce option is not a binding constraint for either spouse in the initial equilibrium, then

(i) an intervention which leads to an increase in any of the variables $k_{m}, \gamma_{m}, k_{c}, \gamma_{c}, k_{f}$, or $\gamma_{f}$, has two distinct effects on decision-making authority within the household as measured by $\lambda$ :

(a) an 'income effect' which is smaller than, equal to, or greater than zero depending on whether the initial value of $\lambda$ is greater than, equal to, or smaller than $\lambda_{e}(y)$;

(b) a 'threat-point effect' which, in the case of an intervention in the male (female) sphere of activity, is greater than zero if and only if $\tilde{y}_{v}^{h}\left(\tilde{V}_{h}^{h}-\lambda \tilde{V}_{h}^{w}\right)<0$ $\left(\tilde{y}_{v}^{w}\left(\lambda \tilde{V}_{w}^{w}-\tilde{V}_{w}^{h}\right)>0\right)$; the effect is absent in the case of a cooperative activity. 
(ii) a small increase in $y_{e}^{h}$ or $y_{e}^{w}$, such that the constraints imposed by the divorce options continue to be slack, will have no impact on $\lambda$; for a sufficiently large increase in $y_{e}^{i}, i \in\{h, w\}$, the constraint for spouse $i$ will begin to bind, and $\lambda$ will shift in favour of this spouse.

Proposition 2.1, which provides a generalisation of 'Result 1' in the previous section, highlights the difference between a development intervention targeted at the cooperative sphere within the household and one that improves skills or enables capital buildup within the autonomous sphere of either spouse. In the former case, the intervention produces only an 'income effect': since the difference in welfare levels associated with non-cooperative threat points become smaller in relation to the utility possibility frontier as household income grows larger, the income effect shifts the household, roughly, closer to a situation where the spouses attained the same level of welfare under non-cooperation. ${ }^{22}$ Therefore, decision-making within the household grows more egalitarian. Raising the income potential of a spouse under non-cooperation also creates an income effect; but it can have an additional effect on decision-making authority if it disproportionately affects the threat-points of the two spouses. Intuitively, raising the autonomous income of one spouse creates 'spill-overs' on the welfare of the other spouse under non-cooperation if they both have strong preferences for certain household public goods; thus, 'threat-point effect' is smaller when the household spends a larger share of its budget on household public goods, as opposed to private goods..

If the divorce threat-point is a binding constraint for either spouse in the initial situation, the general case, and the underlying intuition corresponds exactly to Results 2 and 3 for the special case with exponential utility discussed in the previous section. The results are summarised below.

Proposition 2.2. Suppose the bargaining problem has a corner solution with $w$ receiving the same utility in the agreement as she would from her exit option. Then,

(i) an increase in $k_{m}$ or $\gamma_{m}$ will lead to an increase in $\lambda$;

(ii) a small increase in $k_{s}$ or $\gamma_{s}$, for $s=f$ or $c$, such that w's constraint continues to bind following the increase, will lead to an increase in $\lambda$; for sufficiently large increases in these variables, $w$ 's constraint becomes slack and the the impact on $\lambda$ is as described by Proposition 2.1(i).

\footnotetext{
${ }^{22}$ This is also a generalisation of a result earlier noted by Kanbur and Haddad (1994).
} 
(iii) an increase in $y_{e}^{w}$ will lead to a decrease in $\lambda$; a small increase in $y_{e}^{h}$ will have no impact on $\lambda$ but a sufficiently large increase in $y_{e}^{h}$ will lead to the dissolution of marriage.

\section{Access to Credit}

In section 2.1, it is assumed that the household has no means of acquiring or disposing off assets. In particular, the household had no means to save, or access to credit, in order to buy new assets. We now introduce a microcredit programme into this environment, and examine its effects on household production and decision-making. A loan product is described by a 4 -tuple $\mathcal{L}=(L, z, n, \sigma)$ where $L$ is the size of the loan, which must be repaid, including interest, in equal installments of $z$ over $n$ periods; and $\sigma \in[0,1]$ is the fraction of each loan installment that the husband is obliged to pay in the event that cooperation between the spouses breaks down. This last parameter may be determined by the terms of the loan, informal understanding with the bank officer, or by the relevant social norms.

If the size of the loan is small, and investments are lumpy, say the purchase of a cow or a plot of land, then it may well be that the loan will be invested exclusively in one sphere of production within the household. In the subsequent analysis, this is our working assumption.

The presence of a microcredit programme implies that the household has to decide not only on the allocation of labour across productive activities and household expenditures, but also, when a new loan is available, on whether or not to take out a loan and, if they do, on how to invest the loan. Therefore, we add two additional stages to those introduced in section 2.1 to model decision-making within each period:

Stage P: If the household has access to a credit programme, each spouse states a preference, $P^{i} \in\{Y, N\}$ about whether or not to participate. The household's decision is determined by the function $P\left(P^{h}, P^{w}\right):\{Y, N\} \times\{Y, N\} \longrightarrow\{Y, N\}$.

Stage I: If $P=Y$, then the household receives a loan of size $L$; and each spouse states a preference, $I^{i} \in\{m, f, c\}$ about the activity in which the loan money should be invested. The household's decision is determined by the function $I\left(I^{h}, I^{w}\right):\{m, f, c\} \times$ $\{m, f, c\} \longrightarrow\{m, f, c\}$. The new level of capital in the activity, $s$, chosen for investment, becomes $k_{s}+L$. 
The functions $P($.$) and I($.$) , which define how the household members' preferences for$ borrowing and investment translate into a collective household decision, will be defined in the next section.

We assume that there is full enforcement in loan repayment. Therefore, the presence of an outstanding loan lowers the disposable income of household member i under noncooperation to $y_{a}^{i}-\sigma^{i} z$ in each period. Also, while there is an outstanding debt, a cooperative agreement specifies how to allocate the total disposable income $y-z$. Stages $\mathrm{P}$ and I are followed by stages 1-3 as defined above, except for the adjustments to disposable income indicated here.

During the time interval that the household is obliged to repay the loan, non-cooperation involves having to pay some part of the installment out of one's own autonomous income. The cost of non-cooperation during the time interval that the loan is being repaid depends on the installment shares $\sigma$ and $1-\sigma$, and is thus different from that after the loan has been fully repaid. Therefore, full repayment of the loan will potentially lead to a shift in bargaining powers within the household and cause any previous agreement in the allocation of resources to be renegotiated ${ }^{23}$. Following the reasoning used in the previous section, the equilibrium allocation of resources after full repayment can be represented by $\lambda\left(\mathbf{k}+e_{s} L, \boldsymbol{\gamma}, \hat{\mathbf{y}}_{e}\right)$ where $s$ is the activity sphere in which the loan of size $L$ has been invested and the vector $\hat{\mathbf{y}}_{e}=\left(\hat{y}_{e}^{h}, \hat{y}_{e}^{w}\right)$ represents (stochastic) income levels from exiting the marriage following the introduction of the credit programme.

The allocation of resources during loan repayment is a more difficult problem because, in this case, bargaining is taking place in a non-stationary environment. Each period brings closer the date when the last installment will be repaid and therefore, in theory, the strategic incentives of the spouses will change over time such that an offer that is acceptable in some period $t$ may no longer be acceptable in period $t+1$. In our modelling, we abstract away from the problem of non-stationarity by arguing that when the date of the final installment is weeks or months distant, the spouses should bargain as if they are negotiating in a stationary environment. In reality, a counter-offer may require no more than a few hours (if not minutes) while experiments with bargaining games, and more generally repeated games, have shown that subjects do not engage in backward induction reasoning for more than a few periods (Selten and Stoecker, 1986; Johnson

\footnotetext{
${ }^{23}$ Indeed, since we have assumed that the time interval between offers is close to zero, any previous agreement will always be renegotiated after the last installment is paid unless the initial agreement corresponds exactly to the equilibrium of the continuation game from that point onward.
} 
et al., 2002). Therefore it seems reasonable to assume that when bargaining over an allocation of resources, spouses do not take into account that each new round of a offer and counter-offer brings closer the event of full repayment of the loan. On the other hand, they should consider the implications of full repayment on the decision whether or not to exit the marriage because no backward induction reasoning is necessary here. Hence, we write the solution to the bargaining problem while a loan $\mathcal{L}$ is being repaid, as follows:

$$
\hat{\lambda}\left(\mathbf{k}_{1}, \boldsymbol{\gamma}, \mathbf{y}_{e}, \mathcal{L}\right)=\arg \max _{\lambda \in[0,1]} \prod_{i=h, w}\left[V^{i}\left(y^{i}-z, \lambda\right)-\tilde{V}^{i}\left(y_{a}^{h}-\sigma^{h} z, y_{a}^{w}-\sigma^{w} z\right)\right]
$$

subject to

(9) $\sum_{t=1}^{n} \beta^{t-1} V^{i}(y-z, \lambda)+\sum_{t=n+1}^{\infty} \beta^{t-1} V^{i}\left(y, \lambda\left(\mathbf{k}_{1}, \gamma, \hat{\mathbf{y}}_{e}\right)\right) \geq \sum_{t=1}^{\infty} \beta^{t-1} E \hat{V}^{i}\left(\hat{y}_{e}^{i}\right)$ for $i=h, w$

where $\hat{\lambda}\left(\mathbf{k}, \boldsymbol{\gamma}, \mathbf{y}_{e}, \mathcal{L}\right)$ is the husband's share in total income, $\beta=1-\alpha, L=(L, z, n, \sigma)$, $\mathbf{k}_{1}=\mathbf{k}+e_{s} L$, and $y, y_{a}^{h}$, and $y_{a}^{w}$ are as defined in the preceding section for household assets $\mathbf{k}_{1}$.

It is evident from (8) that the bargaining outcome during the period of repayment is influenced by $\sigma$ and $1-\sigma$, the shares of the installment for which the husband and the wife bear responsibility under non-cooperation. We can argue that these shares should be related to the relative decision-making authorities of the spouses when they opt for the programme, since whoever is perceived to be the primary decision-maker within the household at the time the loan is given is likely to be held accountable (by the enforcement authority, which may be the bank or a peer group) for repayment if an installment is overdue. This argument does not in itself suggest a value for $\sigma$ as it is fraction of a sum of money while $\lambda$ is a weight on utility, but it does indicate that the obligation to repay installments should not significantly shift the balance of power within the household.

3.1. Participation and Investment. From the previous discussion, it is evident that if the loan is invested in an activity over which one spouse has full control rights, this can potentially weaken the relative bargaining position of the other. For this reason, specific household members may prefer not to invest a loan where it has the highest return, or not participate in a credit programme at all even if the return on investment is higher than the rate of interest. To investigate how the spouses' strategic interests would impact upon the household's collective decision regarding participation and investment, we need to specify the functions $P($.$) and I($.$) introduced in the previous section. We consider$ four cases for mapping individual preferences into household decisions. 
(a) $P\left(P^{h}, P^{w}\right)=P^{h} ; I\left(I^{h}, I^{w}\right)=I^{h}$

(b) $P(Y, Y)=Y, P\left(P^{h}, P^{w}\right)=N$ if $P^{h}=N$ or $P^{w}=N ; I\left(I^{h}, I^{w}\right)=I^{h}$

(c) $P(Y, Y)=Y, P\left(P^{h}, P^{w}\right)=N$ if $P^{h}=N$ or $P^{w}=N ; I\left(I^{h}, I^{w}\right)=I^{w}$

(d) $P\left(P^{h}, P^{w}\right)=P^{w} ; I\left(I^{h}, I^{w}\right)=I^{w}$

Case (a) represents the situation where the husband can always overrule his wife's choice regarding financial matters, which may accurately reflect financial decision-making in societies and households with strongly patriarchal norms. Given that participation in a microfinance programme is a public and formal activity, it is doubtful that microfinance providers would lend money to a woman without the husband's approval as they rely on the resource base of the whole household for ultimate repayment of the loan. Rahman (1999) provides a number of narratives involving borrowers of Grameen Bank which illustrates this mechanism.

Cases (b) and (c) represents situations where participation requires the consent of both spouses. If the credit programme offers loans to women only, then the wife must be involved in the physical process of acquiring the loan (i.e. meeting with the bank officer, attending regular meetings to make payments, etc.) Thus, it is reasonable to suppose that, at least for a subset of households, the loan cannot be secured if she does not wish to participate in the programme. In case (b), the husband still has final say regarding the use of the loan once it has been obtained. But if the wife has sufficient knowledge of business matters and authority within the household, she may also be making the investment decision on her own (see Kabeer $(1998,2001)$ for a number of accounts of households operating along these line). The latter situation is captured by case (c).

Finally, case (d) represents the situation where the wife is able to take the decision whether or not to participate in the programme and how to the invest the money entirely on her own. This case may be an accurate reflection of how decisions are made in highly conflictual households where the husband and the wife have devised a 'divorce within marriage', which we will discuss further in the next section.

The appropriate case may well vary across households, and may be related to the initial value of $\lambda$. However, since the participation and investment decisions are made over discrete choices, the non-cooperative bargaining models discussed in the previous section do 
not provide any insight about the relationship between these cases and the non-cooperative threat points and exit options (in the Rubinstein-Stahl bargaining game, agents have a continuum of choices). Nevertheless, we shall loosely associate case (a) with households where the wife has the least say in decision-making, and cases (c) and (d) with households where the wife has the most say. Moreover, it may be argued that if the loan is targeted exclusively at women rather than men, then cases (b) and (c) are more likely to arise than case (a).

Ordering of Investment Choices: The following proposition provides a ranking of all possible investment choices for each spouse:

Proposition 3.1. (i) If the divorce threat constraint binds for spouse $j$ for some investment choices, then spouse i prefers the most efficient investment among them;

(ii) if the divorce threat constraint binds for spouse $i$ for some investment choices, then spouse $i$ is indifferent among them;

(iii) among investment choices for which the divorce threat constraint does not bind for spouse $i$, he (she) prefers the efficient investment unless there is another choice for which the loss in income is compensated, in welfare terms, by a strengthening of decision-making authority;

(iv) spouse $i$ always prefers an investment for which his or her divorce threat constraint is slack to another for which the constraint binds.

There are two key implications of Proposition 3.1. The first is that if the divorce threat constraint binds for spouse i for each of the three possible investment choices, then she (he) is indifferent among them. This is because, by construction, the allocation of resources within the household provides her exactly the level of welfare she would obtain from leaving the marriage for all these choices. Moreover, the other spouse, spouse j, would prefer the most productive of the investments as, by Proposition 2.2(ii), all income gains from the investment will accrue to him (her). This is a special case, but it is one worthy of consideration because, if the size of the loan is small, and the divorce threat constraint is initially binding for either spouse, then it is plausible that the constraint would continue to bind, however the money is invested. 
The second implication is that if there is more than one investment choice for which the divorce threat constraint does not bind for a spouse, then she (he) ranks them by comparing the loss in household income from an inefficient investment, and the gain in bargaining power from doing so. She may not choose the most efficient investment if the efficiency loss from diverting the loan is relatively small, and one or more choices lead to a significant shift in relative bargaining powers

In the context of the empirical literature, Proposition 3.1 highlights the conditions under which a husband who has final say in the investment decision may divert a loan that has its most efficient use in the female autonomous sphere. The proposition indicates that the risk of appropriation of the loan by the husband is high when he has an alternative investment plan which can generate comparable returns, and the share of the household budget spent on household public goods is small (as previously discussed, the latter condition ensures that additional capital in an autonomous activity within the household would lead to a significant shift in bargaining power).

Preferences regarding the participation decision: The participation decision becomes salient when the terms of the loan are not very attractive and the household has limited scope for using additional capital for productive purposes, such that any improvement in welfare from using the loan would be marginal. As with any investment decision, the spouses may differ in terms of the discount factor or in the rate of intertemporal substitution. But, in a bargaining context, there is an additional cause of discrepency between their preferences, which is that taking out and investing a loan may potentially lead to a shift in decision-making authority within the household, favouring one spouse at the expense of the other. As a result, a loan may not be taken up even if the household's preferred investment choice causes the utility possibility frontier to shift outward; i.e. there is scope for diving the gains from the investment to make both spouses better off. And a loan may be taken up even if the subsequent investment causes the pareto frontier to contract everywhere. In the latter case, what makes the loan attractive is not the scope of a profitable investment but, from the point of view of the spouse who has final say in the participation decision, its effect on bargaining power within the household. To formalise these ideas, we introduce the concept of $\lambda$-rationality as below:

Definition 3.1. An investment in activity $s$ is $\lambda$-rational if both spouses prefer the investment to no investment if all allocations are made on the basis of a pareto weight of $\lambda$ 
for the female spouse; i.e.

$$
\sum_{t=1}^{n} \beta^{t-1} V^{i}\left(y_{1}-z, \lambda\right)+\sum_{t=n+1}^{\infty} \beta^{t-1} V^{i}\left(y_{1}, \lambda\right) \geq \frac{1}{1-\beta} V^{i}\left(y_{0}, \lambda\right)
$$

for $i=h, w$.

The significance of the concept of $\lambda$-rationality is that if an investment is $\lambda$-rational for each $\lambda \in(0, \infty)$, then the utility possibility frontier in the presence of an investment is pareto-superior to the frontier without such an investment; and if an investment is not $\lambda$-rational for any $\lambda \in(0, \infty)$, then the utility possibility frontier in the absence of an investment is pareto-inferior to the frontier following such an investment. It should be clear that if the participation decision is consensus-based, then participation will occur only if the preferred investment is $\lambda$-rational for the initial value of $\lambda$.

However, if the participation decision is made unilaterally by one spouse, then $\lambda$-rationality at the initial value of $\lambda$ is neither a necessary condition, nor a sufficient condition, for participation to take place. In particular, if the household's preferred investment satisfies $\lambda$-rationality for the initial value of $\lambda$, but only by a small margin for a spouse who has veto power regarding participation, then the loan may not be taken up, especially if investing the loan leads to a significant shift in bargaining power.

In highly patriarchal societies, where the husband is likely to have final say in the participation decision, he may veto participation for fear of losing his bargaining power, especially if the best use of the loan, once taken, is to invest it in the female autonomous sphere. The theoretical results regarding participation are summarised in the following proposition.

Proposition 3.2. (i) If the participation decision is consensus-based, then $\lambda$-rationality for the initial value of $\lambda$ is a necessary condition for participation to occur; (ii) If the participation decision is made unilaterally by one spouse, then participation may occur even if the household's preferred investment is not $\lambda$-rational for any $\lambda \in(0, \infty)$; (iii) $\lambda$-rationality for the initial value of $\lambda$, or for each $\lambda$, is not a sufficient condition for participating in a loan programme, whether the decision is made unilaterally by one spouse or requires consensus between the spouses.

3.2. Heterogenous Impact of Credit Programmes across Households. The theoretical framework introduced in sections 2.1 and 3 allow us to address the following 
question: Under what conditions is a woman likely to experience an improvement in welfare and decision-making authority within the household as a result of access to credit?

Numerical Solutions: The parameters of the model provide a large set of possible initial conditions for the household. To illustrate the scope of heterogeneous impacts, we compute numerical solutions for a range of values of the productivity parameters $\gamma_{m}, \gamma_{f}$ and $\gamma_{c}$.

Specifically, we fix $\gamma_{m}=4$ and allow $\gamma_{f}$ to vary between 1 and 8 , and $\gamma_{c}$ between 2 and 16. We assume that, initially, the household owns 4 units of capital specific to the male activity, and 2 units of capital in each of the other two (female and joint) activities. We consider a loan size equivalent to 2 units of capital, which requires repayment in 12 equal installments, each worth 0.2 units of capital. The loan must be invested in a single activity. The time discount rate for the period between each installment is assumed to be 0.9 for both spouses.

We model non-cooperation according to the 'separate spheres model', developed by Lundberg and Pollak (1993): there are two household public goods, one in the 'sphere' of each spouse, and, under non-cooperation, one is able to provide only for the public good that lies in one's own sphere. Utility is assumed to take the same logarithmic form for both spouses, with a coefficient of 0.3 for the private good, and a coefficient of 0.35 for each of the household public goods (therefore, each spouse would prefer to spend $60 \%$ of the total budget on his or her private good, and $35 \%$ of the budget on each of the household public goods). We allow for spouses to make transfers to each other under non-cooperation. No transfers wil occur between non-cooperative spouses if they have similar autarkic income levels - this corresponds to case (i) in Section 2.3; but they will occur if one spouse is much richer than the other in autarky - which is represented in case (ii) in Section 2.3.

Figure 1 indicates, for each spouse, the preferred investment choice, or the preference not to participate in the loan programme, for different $\gamma$ values. As expected, both spouses prefer investing the loan in the cooperative activity when their joint productivity in the cooperative activity is relatively high. For lower values of $\gamma_{c}$, each spouse prefers an investment in his or her own activity even when the other is relatively more productive. Only when the wife is assumed to be twice as productive as the husband do we observe a case where the husband would prefer an investment in her activity (for an intermediate level of productivity in the cooperative activity). From the two figures, it is evident that 
if the husband has final say over the choice of investment, then the loan would rarely be employed in the female activity, even if the wife has strong skills in this activity.

On the other hand, if the household's productivity in the joint activity is high, the husband opts to invest in this activity; this leads to a more egalitarian allocation of resources within the household and, in particular, leads to an improvement in the wife's bargaining power (since she is initially in a weaker position; this follows from Proposition 2.1, part (i)). Indeed, if the husband has final say in how the loan is to be used, her bargaining power improves only if the couple is sufficiently productive in the joint activity compared to the male activity (except in the sole case noted above).

It is also evident from the two figures that the loan may be invested in the female activity when $\gamma_{f}$ is relatively high, and the wife has final say in the investment choice. But we would like to argue that, in terms of the empowering potential of microfinance, this case is less interesting: if the wife can opt to invest the loan in her own activity even though the husband would prefer otherwise, it must be that she is, in some sense, already empowered in terms of decision-making authority within the household.

The numerical model also illustrates a situation where the wife is indifferent between the three investment choices as well as the no participation option. This occurs when the level of productivity in both the female and cooperative sphere are low relative to that in the male sphere. The wife's divorce threat constraint is binding, and therefore a (relatively small) investment in any household activity would have no impact on her welfare (Propositions 2.2 and 3.1). However, if the size of the loan were large enough, she would have a clearer preference among the different investment options.

For all the parameter values considered above, both spouses are better off, or at least no worse off, from participating in the loan programme. To explore further issues around participation, we consider a different case where the household has a larger asset base (and therefore lower returns to capital) and is offered a smaller loan at a higher interest rate. The preferences of the two spouses regarding participation and investment choice for different $\gamma$ values are represented in Figure 2 (the exact parameter values are provided in the figure). The figure shows, in particular, a range of $\gamma$ values for which one spouse would prefer to participate in the programme while the other would not. The wife, for instance, would prefer not to participate when there is little scope for autonomous producton for her within the household, as well as little scope for joint production. But, for some of these values, the husband would actually prefer taking the loan and investing it in his own 
activity. As $\gamma_{f}$ increases, i.e. the wife becomes more productive in her activity, she would prefer making an investment in her activity, but the husband, on the other hand, would prefer not to participate in the programme for fear of weakening his bargaining power.

In Figure 3, we present the results for a different set of simulation for the case where each spouse has a stronger preference for his or her private good (specifically, the logarithmic utility function, with a coefficient of 0.6 for the private good, and a coefficient of 0.2 for each of the household public goods). The results indicate that when the household spends a smaller share of its budget on household public goods, both spouses are less likely to prefer for an investment in the cooperative activity over an investment in their own activity.

Illustration with an ethnographic study: The stylised framework of the household economy we have developed can account for a variety of outcomes described in ethnographic studies regarding household responses to credit programmes. In particular, the theoretical results developed in the preceding sections allow us to distinguish between different types of intra-household relations and predict, in each case, what would be the impact of a microcredit programme that targets women. We shall use the wide array of intra-household relations documented in Naila Kabeer's (1998, 2001) study of women participating in the SEDP credit programme in the Bangladesh to illustrate the model's predictions.

First, consider a household for which $\gamma_{c}$ is very small relative to $\gamma_{m}$ and $\gamma_{f}$. Then, in equilibrium, each spouse allocates all of his or her labour to her autonomous sphere, and consumes the income generated in this sphere. No bargaining takes place within the household as there is no surplus to bargain over. These parameter values can represent an extremely conflictual relation within the household, where there is no scope for the spouses to cooperate in a joint activity. Kabeer (2001), in providing a characterisation of women borrowers in a microcredit programme in Bangladesh, refers to such a situation as one of "divorce within marriage", wherein women were able to use their loans "to create a parallel economy for themselves which gave them considerable financial independence from their husbands" (Kabeer 2001, p.74). In terms of the model, if the availability of credit enables the woman to become more productive in her autonomous activity, then the gains will necessarily accrue to her. As her husband receives only the income from his own activity, his welfare will be unaffected. Thus, we have an example where the woman's access to credit has a direct, unambiguously positive impact on her welfare. 
Second, consider a household where $\gamma_{f}$ is small relative to $\gamma_{c}$ and $\gamma_{m}$. In this case, the woman has few options to provide for herself if cooperation breaks down in the household. As her non-cooperative threat-point is weak, the man may be able to extract all the surplus above her utility from exit. In this situation, the availability of credit will not improve the woman's welfare, in whichever activity the loan may be used. As stated in Proposition 2.2, all income gains from a (small) increase in the household's productive assets will accrue to the man and, indeed, there will be a strengthening in his bargaining position. Kabeer (1998) provides a number of examples of women borrowers whose situation corresponded well with the outcome predicted in Proposition 2.2. Although the household relied on them for access to credit and, in some instances, they made substantial labour contributions to the loan-related activity, they had no control over - and sometimes little knowledge of the income generated using their loans.

Third, consider a household where $\gamma_{c}$ is high relative to both $\gamma_{m}$ and $\gamma_{f}$. This means that both spouses provide valuable inputs in a cooperative activity. This may be a female enterprise in which the man provides essential inputs like marketing or a male enterprise where the woman's input is highly valued. Kabeer $(1998,2001)$, provides a number of accounts of marriages that can be placed in one or the other of these categories. If the most productive use of additional capital is in the cooperative sphere, then the introduction of a credit programme will further increase $\gamma_{c}$. In Kabeer's interviews, the women involved in such joint activities (in some cases, 'joint' simply because the woman was the conduit for an essential input, namely credit) indicated that they played an important role in deciding how the profits generated using the loan activity would be used. In this sense, they had experienced an increase in welfare as a result of their access to credit. In terms of the model, if the most productive use of new capital is in the cooperative sphere, then the introduction of a credit programme will lead to an increase in $\gamma_{c}$. Then, as stated in Proposition 2.1, following the increase in capital available for the joint activity, the allocation of household income between the spouses will shift in favour of the more disempowered spouse.

Lastly, consider a household where a microcredit loan would enable a woman to expand her autonomous sphere, and her activity provides the most efficient means for using the loan within the household. However, as implied by Proposition 3.1, if her husband has an alternative means of using capital that retains his bargaining position without sacrificing too much income, he has an incentive to appropriate the loan. In this case, the likely end result of the credit programme would be to weaken the woman's bargaining position 
within the household (Result 1(b) and Proposition 2.1), though her welfare may still improve). It would be difficult to identify instances of such appropriation in empirical studies since it requires being able to distinguish between efficient use of a loan in a male activity and strategic appropriation of the loan by a man to retain his bargaining position. Nevertheless, the man's strategic incentive to appropriate the loan identified in the model may account partly for the large fraction of loans given to women through microfinance programmes being invested in male-dominated activities, as noted earlier.

The numerical solutions and the four scenarios discussed above suggest that the availability of credit allows a woman to strengthen her bargaining position within the household through an expansion of her autonomous activities in a limited number of cases. For this process to occur, it must be that not only is the woman able to invest new capital profitably in an autonomous activity, but also that her husband has no alternative activity in which the same capital would generate comparable returns, or lacks the power to overrule her preferred investment choice. While it is true that in a highly conflictual relationship the availability of credit can improve her welfare, it does not, strictly speaking, enable her to strengthen her bargaining position since there is no marriage surplus to bargain over. We note also that for highly disempowered women, credit interventions will not have any impact on her welfare as all income gains will accrue to the husband. The case in which it is most likely that the availability of credit would enable the woman to strengthen her bargaining position within the household is when capital can be invested in a cooperative activity to which both spouses contribute in an important way.

\section{Conclusion}

Our aim in this paper was to provide a critical perspective on the theory underlying gender targeting in microcredit programmes and its possible effect on intra-household relations. In the literature, this issue is often regarded as being closely related to the question of whether women with greater autonomous control over assets and income within the household have greater say in household decisions, while, in policy discussions, empirical findings on the latter question often serve to motivate or justify targeting women for microcredit. 
To investigate how providing a household access to credit affects the allocation of resources and intra-household decision-making, we developed a simple theoretical framework distinguishing between three alternatives facing individuals within the household - exit, autonomy and cooperation - and the type of production possible under each alternative. Unlike most of the literature on the theory of intra-household allocation, we explicitly model the process of bargaining within the household to examine how the possibility of exit or autonomy affects the decision-making process.

Even this simple framework reveals a wide range of possible outcomes for households provided with access to new credit. Depending on the initial balance of power in the household and the potential of each household member to undertake or participate in an entrepreneurial activity, the introduction of a credit programme may lead to (i) greater cooperation in household production, and a more egalitarian intra-household allocation of resources; (ii) greater autonomy of the woman in productive activities; (iii) appropriation of all additional income generated with the loan by the husband with no change in welfare for the woman; and (iv) strategic appropriation of the loan - or strategic veto of programme participation - by the husband to preserve his bargaining power. The theory can account for the heterogeneity of outcomes across households revealed through careful micro-level studies of micocredit programmes, such as Naila Kabeer $(1998,2001)$ 's work on the impact of the SEDP credit programme in Bangladesh.

Our model demonstrates that the introduction of a microcredit programme is likely to have heterogeneous impacts and also adverse effects on the bargaining power of some women. Important sources of the heterogeneity in programme impact include attitudes of husbands and wives regarding gender norms, the scope for women's autonomy in the community, as well as pre-intervention levels of relative bargaining power in the household. Our theoretical results point to the importance of paying closer attention to the distribution of the gains and losses from the intervention. ${ }^{24}$ To our knowledge, only one impact study has attempted to consider the initial bargaining power of female participants prior to the introduction of a microfinance programme. Ashraf et al. (2008) analyse the impact on access to a savings product on women's decision-making power and find that the

\footnotetext{
${ }^{24}$ This is a point made more broadly by Heckman (2005) regarding the evaluation of economic policies in general and is particularly important to inform policy-making in developing countries. See Ravallion (2008) for the latter point.
} 
positive mean impact was largely driven by initially less-empowered women, while more empowered women did not experience any significant effect. ${ }^{25}{ }^{26}$

Most importantly, the theory underlines the fact that gender targeting in microcredit is not equivalent to providing women with greater autonomous control over new resources. This is because women are placed in situations of unequal interdependence within the family and have thus little scope to develop purely autonomous activities. Moreover, strategic preemptive behaviour by male spouses further restricts women's ability to allocate new loans to their autonomous activities. We show that women may be able to invest in their own independent activities only under special circumstances, for instance in very conflictual households, or when women are already empowered in the household.

Depending on the socio-cultural context, greater individual control over resources may not be feasible without changes in the underlying structure of gender relations. In the impoverished settings in which microfinance projects operate, kinship ties and marriage play an important role in providing individuals with legitimate claims over household and community resources, together with vital access to an insurance network in times of crisis. Hence, cooperation and jointness of decision-making may be more desirable for women than autonomous control over resources. In the words of Kabeer (1998, p.83)

As long as the family, and male guardianship remains women's greatest source of economic and social security, women's interests are likely to be better served by equalising the terms of interdependence within the family rather than seeking to establish their autonomy. The mitigation of their dependent status within the family so that the perceived 'jointness' of family welfare and interests is more equally shared by other members is one means by which this is achieved. In this context, [...] the notion of 'centrality' $[\ldots]$ does seem to better capture the processes described by the women loanees of moving from marginalisation within household decision-making and exclusion within the community to positions of greater centrality, inclusion and 'voice'.

Holding this perspective has important implications regarding our understanding of the empowering potential of microfinance programmes. If the new economic opportunities lie

\footnotetext{
${ }^{25}$ More or less empowered women refer to women above or below the baseline median of their measure of bargaining power respectively.

${ }^{26}$ Note that Karlan (2007) find no impact from access to credit on household decision-making.
} 
outside the traditional realm of the female spouse and exit options for women are severely limited, then she may be better off ignoring it to preserve her social ties within the community. Thus, the empowering potential of microfinance is necessarily circumscribed by prevailing gender norms, unless alternatives are offered to women that strengthen their outside options in a credible manner. The magnitude of this latter effort should not be underestimated. Changing women's outside options requires special efforts and strong political will, as evidenced by the history of women's emancipation in Europe and in developing countries alike. ${ }^{27}$

In addition, because of the possibility of strategic preemptive behaviour on the part of the male spouse, an intervention that requires the cooperation of both spouses or ensures that male spouses also benefit (or do not lose) from it, may be more successful at achieving wider social impacts than interventions that focus on women's autonomous spheres only. However, the difficulty in designing policies that engender cooperation within the household should not be underestimated. Providing incentives for cooperation between spouses $^{28}$ can also be fraught with problems and may have unintended consequences, as evidenced by a study on pastoral women in Northern Kenya (Doss and McPeak 2005). ${ }^{29}$

\footnotetext{
${ }^{27}$ In their study of women's participation in economic activities outside of the household in developing countries, Morrisson and Jutting (2005) conclude: "In sum, if social institutions in developing countries discriminate against women, policy measures aiming to improve their situation via improved access to education and health will have only a limited impact. [...] If custom forbids outside work for women, the enrollment rate of girls in primary schools can double without entailing an increase in female participation in the labor market. If custom goes against accepting that women can be in a position to exercise authority, the enrollment rate in universities can double without increasing the number of women managers. These examples show that to increase the effectiveness of country and donor policies, measures to address the institutional framework have to be undertaken" (pp. 1066, 1078). At the same time, overcoming these social institutional constraints is not easy, as highlighted by Pezzini (2005)'s study of twelve European countries, which shows that abortion rights and the pill did have significant effects on women's welfare, but that other women's rights (e.g. mutual consent divorce laws and high maternity protection on the job) were less effective or even counter-productive.

${ }^{28}$ Armendariz de Aghion and Roome (2008) recently conducted an experiment in Mexico, which consisted in allowing women to invite their husbands to join a Self-Help Group under different scenarios. Results from this experiment are still pending.

${ }^{29}$ The women in question required the cooperation of their husbands to market dairy milk in response to new market opportunities. However, Doss and McPeak (2005) find that instead of cooperating with their wives, men made migration decisions that limited their wives' ability to market milk. Note that Doss and McPeak (2005) are careful not to argue that non-cooperation between spouses over milk marketing and migration decisions will automatically have a negative impact of household welfare. Similarly, it is not obvious that women's milk marketing plans will have positive welfare effects. The welfare impacts of non-cooperation (or contestation to use Doss and McPeak's expression) within the household need to be made explicit and further explored empirically. See also Lundberg and Pollak (2003), who provide a theoretical discussion of such strategic decisions within the household.
} 
A final point worth emphasizing is that, although women may not retain control over their loans during the productive process, loss of control should not necessarily be equated with loss of bargaining power. Instead, as evident from the formal theory on bargaining, the relative bargaining strengths within a couple depend on how much each spouse brings to the productive process in a cooperative agreement; the impact of a microcredit programme depends on how the introduction of new capital reshapes household production, and draws upon the skills and inputs of the two spouses. This result casts a new light on complementary interventions such as entrepreneurship or business training programmes, to the extent that they succeed in increasing the value of a woman's contribution to a cooperative activity in her household.

\section{REFERENCES}

[1] Adam, C, John Hoddinott, and Ethan Ligon. 2003. "Dynamic Intrahousehold Bargaining, Matrimonial Property Law and Suicide in Canada." Oxford University.

[2] Agarwal, B., 1994), A Field of One's Own: Gender and Land Rights in South Asia. Cambridge University Press.

[3] Anderson, Siwan and Mukesh Eswaran. 2007. "What Determines Female Autonomy? Evidence from Bangladesh."

[4] Armendariz de Aghion, Beatriz and Jonathan Morduch. 2005. The Economics of Microfinance: MIT Press.

[5] Armendariz de Aghion, Beatriz and N. Roome. 2008. "Empowering Women Via Microfinance in Fragile States." Centre Emile Bernheim Working Paper, 08/001.

[6] Ashraf, Nava, Dean Karlan, and Wesley Yin. 2008. "Female Empowerment: Impact of a Commitment Savings Product in the Philippines."

[7] Bergstrom, Ted C. 1996. "Economics in a Family Way " Journal of Economic Literature, 34:4, pp. 1903-34.

[8] Binmore, Kenneth George (1985). "Bargaining and Coalitions", in Game-Theoretic Models of Bargaining, ed. Alvin Roth. Cambridge: Cambridge University Press, pp. 259-304.

[9] Bloch, F. and V. Rao, (2002), "Terror as a Bargaining Instrument: A case study of dowry violence in rural India", The American Economic Review, September 2002.

[10] Cull, Robert, Asli Demirguc-Kunt, and Jonathan Morduch. 2008. "Microfinance Meets the Market." World Bank Research Working Paper, 4630.

[11] de Mel, Suresh, David McKenzie, and C Woodruff. 2007. "Who Does Microfinance Fail to Reach? Experimental Evidence on Gender and Microenterprise Returns." BREAD Working Paper.

[12] de Mel, Suresh, David McKenzie, and C Woodruff. 2008. "Returns to Capital: Results from a Randomized Experiment." Quarterly Journal of Economics.

[13] Doss, Cheryl R. and John G. McPeak. 2005. "Are Household Production Decisions Cooperative? Evidence on Pastoral Migration and Milk Sales from Northern Kenya." Economic Growth Center Yale University Discussion Paper, 906.

[14] Duflo, Esther. 2005. "Gender and Development."

[15] Edmonds, Eric V. 2005. "Does Illiquidity Alter Child Labor and Schooling Decisions? Evidence from Household Responses to Anticipated Cash Transfers in South Africa." Journal of Development Economics, forthcoming.

[16] Emran, Shahe, Mahmud Morshed, and Joseph Stiglitz. 2006. "Microfinance and Missing Markets." 
[17] Fafchamps, M., Bereket Kebede, and Agnes Quisumbing. 2006. "Intrahousehold Welfare." mimeo.

[18] Goetz, Anne Marie and Rina Sen Gupta. 1996. "Who Takes the Credit? Gender, Power, and Control over Loan Use in Rural Credit Programs in Bangladesh." World Development, 24:1, pp. 45-63.

[19] Hartmann, B. and J. Boyce, (1983). A Quiet Violence: View from a Bangladesh Village. Zed Books, London.

[20] Hashemi, Syed, Sidney Ruth Schuler, and Ann Riley. 1996. "Rural Credit Programs and Women's Empowerment in Bangladesh." World Development, 24:1, pp. 45-64.

[21] Heckman, J. J. 2005. "The Scientific Model of Causality." Sociological Methodology, 35:1, pp. 1-98.

[22] Johnson, E.J., C. Camerer, S. Seric and T. Rymon, 2002. "Detecting Failures of Backward Induction: Monitoring Information Search in Sequential Bargaining", Journal of Economic Theory, Vol. 104(1), pp. 16-47.

[23] Johnson, Susan. 2004. "Gender Norms in Financial Markets: Evidence from Kenya." World Development, 32:8, pp. 1355-74.

[24] Johnston, Don and Jonathan Morduch. 2007. "Microcredit Vs. Microsaving: Evidence from Indonesia."

[25] Kabeer, Naila. 1998. "Money Can't Buy Me Love? Reevaluating the Empowerment Potential of Loans to Women in Rural Bangladesh." IDS Working Paper.

[26] Kabeer, Naila. 2001. "Conflicts over Credit: Re-Evaluating the Empowerment Potential of Loans to Women in Rural Bangladesh." World Development, 29:1, pp. 63-84.

[27] Kanbur, Ravi and L. Haddad. 1994. "Are Better-Off Households More Unequal or Less Unequal?" Oxford Economic Papers, 46:3, pp. 445-58.

[28] Karlan, Dean. 2007. "Expanding Credit Access: Using Randomized Supply Decisions to Estimate the Impacts."

[29] Khandker, S. 2003. "Microfinance and Poverty: Evidence Using Panel Data from Bangladesh." World Bank Policy Research Working Paper, 2945.

[30] Kihlstrom, Richard E., Alvin E. Roth and David Schmeidler, (1981), "Risk aversion and solutions to Nash's bargaining problem" in Game Theory and Mathematical Economics, ed. by O. Moeschlin and D. Pallaschke. Amsterdam: North Holland..

[31] Ligon, Ethan, (2002), "Dynamic bargaining in households (with an application to Bangladesh).", Giannini Foundation Working Paper.

[32] Lundberg, S. J. and Robert Pollak. 1993. "Separate Spheres Bargaining and the Marriage Market." Journal of Political Economy, 101, pp. 988-1011.

[33] Lundberg, S. J. and Robert Pollak. 1994. "Noncooperative Bargaining Models of Marriage." American Economic Review, 84, pp. 132-37.

[34] Manser, Marilyn and Murray Brown. 1980. "Marriage and Household Decision Theory - a Bargaining Analysis." International Economic Review, 21, pp. 21-34.

[35] Mayoux, Linda. 1999. "Questioning Virtuous Spirals: Micro-Finance and Women's Empowerment in Africa." Journal of International Development, 11:7.

[36] McElroy, Marjorie B. and Mary Jane Horney. 1981. "Nash Bargained Household Decisions: Toward a Generalization of the Theory of Demand." International Economic Review, 22:2, pp. 333-49.

[37] Morrisson, Christian and Johanness P. Jutting. 2005. "Women's Discrimination in Developing Countries: A New Data Set for Better Policies." World Development, 33:7, pp. 1065-81.

[38] Mullany, Britta C., Michelle Hindin, and Stan Becker. 2005. "Can Women's Autonomy Impede Male Involvement in Pregnancy Health in Katmandu, Nepal?" Social Science \& Medicine, 61.

[39] Ngo, Thi Minh Phuong. 2008. "Microfinance and Gender Empowerment in Kyrgyzstan." Prepared for The World Bank - Agriculture and Rural Development Department (ARD).

[40] Pezzini, Silvia. 2005. "The Effect of Women's Rights on Women's Welfare: Evidence from a Natural Experiment." Economic Journal, 115:502, pp. C208-27.

[41] Pitt, Mark, Shahidur Khandker, and Jennifer Cartwright. 2006. "Empowering Women with Microfinance: Evidence from Bangladesh." Economic Development and Cultural Change, pp. 791-831. 
[42] Pollack, R.A. 1994. "For Better or Worse: The Role of Power in Models of Distribution within Marriage." American Economic Association Papers and Proceedings, 84:2, pp. 148-52.

[43] Rahman, Aminur. 1999. Women and Microcredit in Rural Bangladesh : Anthropological Study of the Rhetoric and Realities of Grameen Bank Lending. Boulder: Westview Press.

[44] Ravallion, M. 2008. "Evaluation in the Practice of Development." World Bank Policy Research Working Paper, 4547.

[45] Roth, Alvin, (1979), Axiomatic Models of Bargaining. Berlin: Springer.

[46] Rubinstein, Ariel (1982). "Perfect Equilibrium in a Bargaining Model", Econometrica, 50, pp. 97-109.

[47] Rutherford, Stuart. 2006a. "Members' Savings." MicroSave Briefing Notes on Grameen II 2.

[48] Rutherford, Stuart. 2006b. "What Is Grameen II? Is It up and Running in the Field Yet?" MicroSave Briefing Notes on Grameen II, 1.

[49] Rutherford, Stuart. 2002. "Money Talks: Conversations with Poor Households in Bangladesh About Managing Money." IDPM Finance and Development Research Programme Working Papers 45.

[50] Selten, R. and R. Stoecker, 1986. "End Behavior in Finite Prisoners' Dilemma Supergames", Journal of Economic Behavior and Organization, Vol. 7, pp. 47-70.

[51] Thomas, D., Dante Contreras, and Elizabeth Frankenberg. 2002. "Distribution of Power within the Household and Child Health."

[52] Van Tassel, Eric, (2004), "Household Bargaining and Microfinance", Journal of Development Economics

[53] White, S.C., (1992), Arguing with the Crocodile: Gender and Class in Bangladesh. Zed Books, London.

[54] World Bank. 2001. "Engendering Development through Gender Equality in Rights, Resources, and Voice." World Bank Policy Research Report 